\section{How to Define Baseline Erosiveness to Predict Radiologic Progression in Rheumatoid Arthritis}

\section{To the Editor:}

Baseline erosiveness is a potent predictive factor used in daily practice for predicting a severe destructive disease course in rheumatoid arthritis (RA). However, there is no uniform definition of erosive disease at disease onset The definitions used in some studies were highly variable: radiological evidence of erosions ${ }^{1,2}$, a cortical break $\geq 2 \mathrm{~mm}^{3}$, or presence of $\geq 2$ or $\geq$ 3 erosions ${ }^{4,5}$. The lack of a generally accepted definition makes studies on this subject difficult to compare. Moreover, it prevents the use of radiological information at disease presentation in a consistent manner in clinical practice.

The radiologic criterion to classify RA, according to the 2010 criteria, was presented and defined as the presence of at least 3 erosive joints ${ }^{6,7}$. An erosive joint was defined as a metacarpophalangeal (MCP), proximal interphalangeal (PIP), metatarsophalangeal (MTP), or wrist joint with a broken cortex on a radiograph. This measure is easily applicable in clinical practice. This prompted us to (1) evaluate the accuracy of baseline erosiveness expressed by the number of erosive joints to predict radiographic progression in the short term and long term; and (2) to evaluate whether an optimal cutoff for the level of baseline erosiveness to predict severe joint damage progression can be determined.

Patients with early arthritis, included between 1993 and 2006 in the Leiden Early Arthritis Clinic and who were diagnosed with RA at firs presentation (according to the 1987 or the 2010 criteria), were studied ( $\mathrm{n}=$ $701)^{8}$. Serial hand and foot radiographs were taken at first presentation and on a yearly basis during followup. The number of joints with a cortex break was determined from the baseline radiographs, assessing bilateral MTP, PIP, MCP, and wrist joints. Two outcomes were assessed: rapid radiological progression (RRP) on the short term and longterm progression of joint destruction during 7 years of disease. RRP was defined as an increase $\geq 5$ Sharp-van der Heijde (SHS) points in 1 year, a change larger than the smallest detectable difference that is also associated with functional decline $^{9}$. The serial radiographs were SHS scored by 2 readers; the within-reader ICC was 0.87 and 0.91 , the between-reader ICC was 0.89 . Relations between the number of erosive joints and the progression of joint destruction over a maximum followup period of 7 years were tested by multivariate normal regression analyses, taking advantage of within-patient correlations between serial radiologic measurements ${ }^{10}$. Analyses were adjusted for age, sex, and inclusion period, as a proxy for different treatment strategies. The treatment strategy applied was different in different periods; patients included 1993-1995 were initially treated with nonsteroidal antiinflammatory drugs, patients included 1996-1998 were initially treated with chloroquine or sulfasalazine, and patients included after 1999 were promptly treated with methotrexate. Only $4.7 \%$ of the patients were treated with anti-tumor necrosis factor agents at any time during the followup period ${ }^{10}$.

Six hundred eighty-seven patients had baseline radiographs. The baseline characteristics are shown in Table 1A. In 550 patients, a

Table 1. Characteristics of RA patients with different numbers of erosive joints at first presentation (A) and the test characteristics and predictive values for developing rapid radiological progression during the first year of the disease (B).

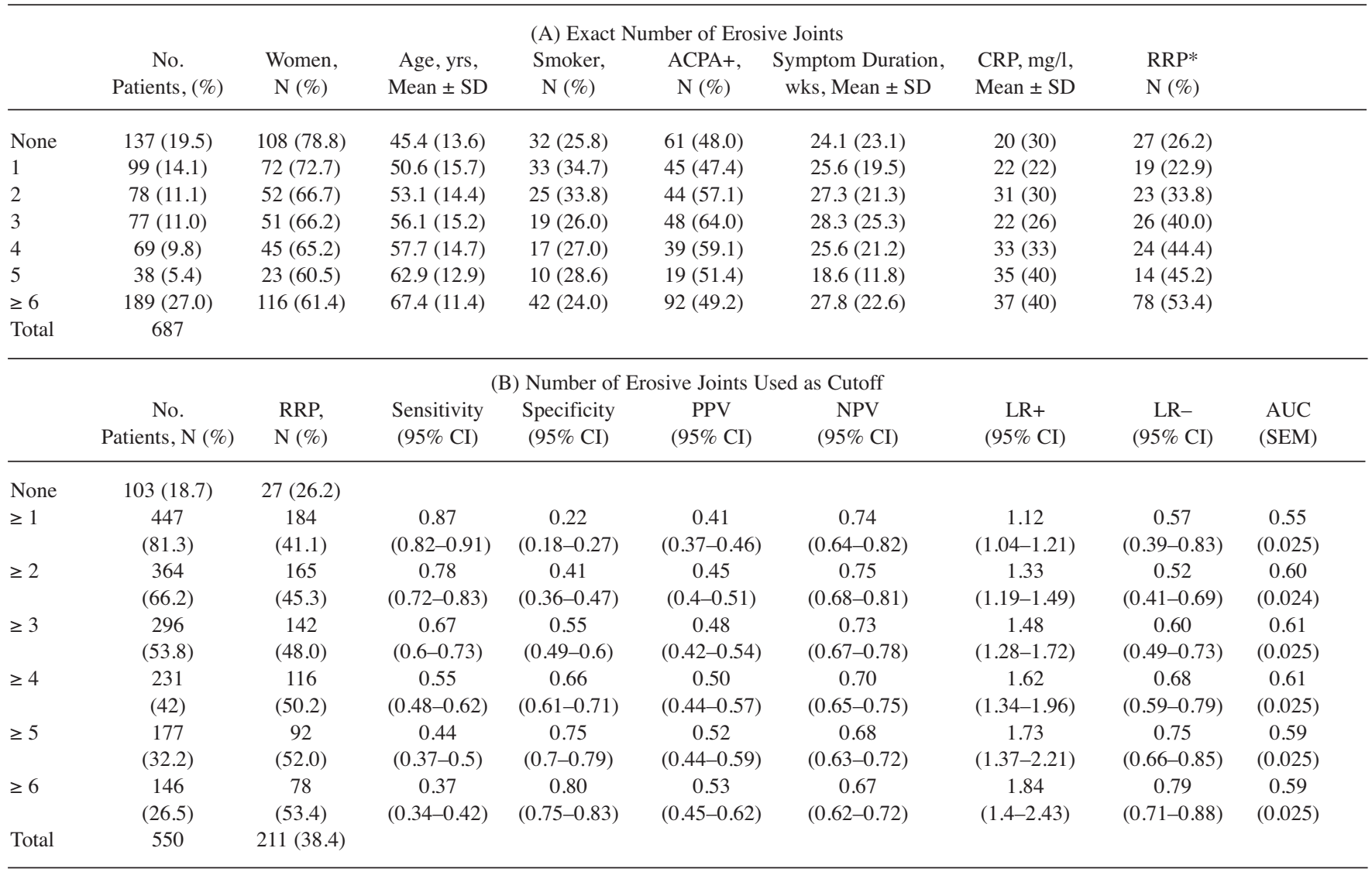

* Not all patients had a radiograph 1 year post-followup. In 550 patients, the presence of rapid radiological progression (RRP) could be calculated. ACPA: anticitrullinated protein antibodies; CRP: C-reactive protein; PPV: positive predictive value; NPV: negative predictive value; LR: likelihood ratio; AUC: area under the curve; RA: rheumatoid arthritis.

Personal non-commercial use only. The Journal of Rheumatology Copyright $\subset$ 2013. All rights reserved. 
radiograph was taken at both baseline and Year 1. In total, 211 patients (38.4\%) had RRP; this frequency increased per category of erosive joints (Table 1A). Subsequently, patients were categorized using different numbers of erosive joints as cutoff for baseline erosiveness (Table 1B). With every increase in number of erosive joints as cutoff, the specificity and positive likelihood ratio (LR+) increased but the sensitivity and LR- decreased. The area under the curve was the highest for the cutoffs $>$ 3 or $>4$ joints, but the differences were small. Subsequently, the progression in SHS scores over 7 years of followup for RA patients with different numbers of erosive joints at first presentation was studied. Additionally, the SHS scores over 7 years were studied when different numbers of erosive joints were used as cutoffs and patients were grouped accordingly (Figure 1). Every increase in cutoff was associated with more severe SHS progression, and no clustering of lines was observed.

As one may expect, every increase in the number of erosive joints at RA onset is associated with an increased chance of short-term and longterm progression of joint damage. Although further studies in other cohorts are required, we could not identify an obvious single cutoff point to define baseline erosiveness in relation to prediction of joint damage progression.

LING YIN HO, MD, Department of Medicine, Tuen Mun Hospital, Hong Kong SAR, China, Department of Rheumatology, Leiden University Medical Center; DIEDERIK P.C. de ROOY, MD, LLM, Department of Rheumatology, Leiden University Medical Center; ANNETTE H.M. van der HELM-van MIL, MD, PhD, Department of Rheumatology, Leiden University Medical Center, Leiden, The Netherlands. Address correspondence to Dr. D.P.C. de Rooy, Department of Rheumatology, Leiden University Medical Center, PO Box 9600, 2300 RC Leiden, The Netherlands. E-mail: d.p.c.de_rooy@lumc.nl

Dr. Ho and Dr. de Rooy contributed equally to this report.

\section{REFERENCES}

1. Bathon J, Robles M, Ximenes AC, Nayiager S, Wollenhaupt J, Durez $\mathrm{P}$, et al. Sustained disease remission and inhibition of radiographic progression in methotrexate-naive patients with rheumatoid arthritis and poor prognostic factors treated with abatacept: 2-year outcomes. Ann Rheum Dis 2011;70:1949-56.

2. Sanmarti R, Gomez A, Ercilla G, Gratacos J, Larrosa M, Suris X, et al. Radiological progression in early rheumatoid arthritis after DMARDS: a one-year follow-up study in a clinical setting. Rheumatology 2003;42:1044-9.

3. Rau R, Herborn G, Menninger H, Sangha O. Radiographic outcome after three years of patients with early erosive rheumatoid arthritis treated with intramuscular methotrexate or parenteral gold Extension of a one-year double-blind study in 174 patients. Rheumatology 2002;41:196-204.

4. Nell-Duxneuner V, Machold K, Stamm T, Eberl G, Heinzl H, Hoefler E, et al. Autoantibody profiling in patients with very early rheumatoid arthritis: a follow-up study. Ann Rheum Dis 2010;69:169-74.

5. Sharp JT, Tsuji W, Ory P, Harper-Barek C, Wang H, Newmark R. Denosumab prevents metacarpal shaft cortical bone loss in patients with erosive rheumatoid arthritis. Arthritis Care Res 2010; 62:537-44.

6. Knevel R, Lukas C, van der Heijde D, Rincheval N, Combe B, van der Helm-van Mil AH. Defining erosive disease typical of RA in the light of the ACR/EULAR 2010 criteria for rheumatoid arthritis; results of the data driven phase. Ann Rheum Dis 2013;72:590-5.

7. van der Heijde D, van der Helm-van Mil AH, Aletaha D, Bingham CO, Burmester GR, Dougados M, et al. EULAR definition of erosive disease in light of the 2010 ACR/EULAR rheumatoid arthritis classification criteria. Ann Rheum Dis 2013;72:479-81.

8. de Rooy DP, van der Linden MP, Knevel R, Huizinga TW, van der Helm-van Mil AH. Predicting arthritis outcomes - What can be learned from the Leiden Early Arthritis Clinic? Rheumatology 2011;50:93-100.

9. van den Broek M, Dirven L, de Vries-Bouwstra JK, Dehpoor AJ, Goekoop-Ruiterman YP, Gerards AH, et al. Rapid radiological progression in the first year of early rheumatoid arthritis is predictive of disability and joint damage progression during 8 years of follow-up. Ann Rheum Dis 2012;71:1530-3.

10. Knevel R, Tsonaka R, Cessie SL, Linden MV, Huizinga T, Heijde $\mathrm{DV}$, et al. Comparison of methodologies for analysing the progression of joint destruction in rheumatoid arthritis. Scand $\mathbf{J}$ Rheumatol 2013;42:182-9.

J Rheumatol 2013;40:9; doi:10.3899/jrheum.130319
A

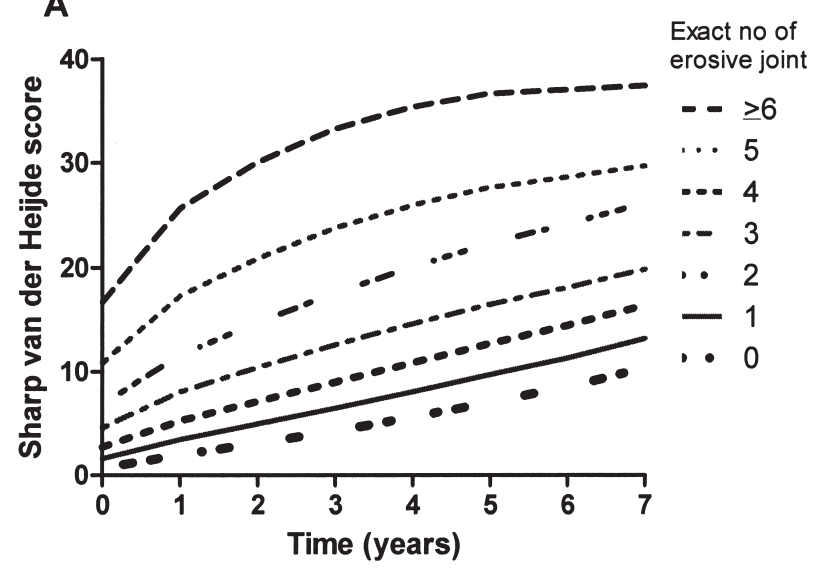

B

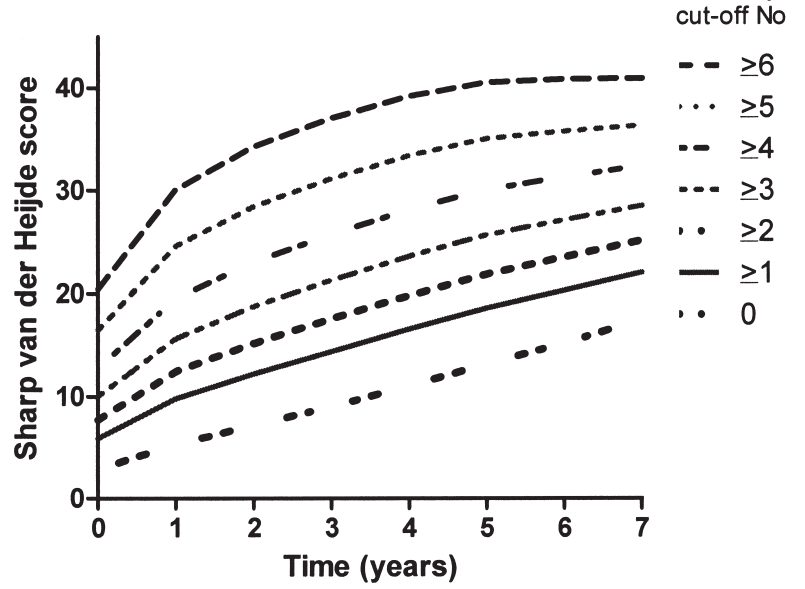

Figure 1. Progression in Sharp-van der Heijde score (SHS) over 7 years of followup for RA patients with different numbers of erosive joints at first presentation (A) and with different numbers of erosive joints used as cutoff (B). Data are predicted by multivariate normal regression analyses ${ }^{10}$, taking advantage of within-patient correlations between serial radiologic measurements and with adjustment for age, sex, and inclusion period (as a proxy for different treatment strategies). A. SHS data are presented for the absolute number of erosive joints. B. The cutoff for erosiveness is defined using different numbers of erosive joints.

Personal non-commercial use only. The Journal of Rheumatology Copyright @ 2013 . All rights reserved. 